\title{
Antioxidant Activity of Phenolic Compounds from Different Grape Wastes
}

\section{Souad EI Gengaihi' ${ }^{* 1}$ Faten M Aboul Ella², Emad M H, Emad Shalaby² and Doha H $^{1}$}

${ }^{1}$ Medicinal and Aromatic Plant Department, Pharmaceutical Division, National Research Centre, Cairo, Egypt

${ }^{2}$ Biochemistry Department, Faculty of Agriculture, Cairo University, Giza Egypt

\begin{abstract}
Winery pomace (from red and white grapes) was extracted under various conditions using different solvents. The antioxidant activity of solvent extracts was investigated by DPPH radical scavenging method. Ethanol extract exhibited the highest antioxidant activity compared to the other solvent $\left(\mathrm{BuOH}, \mathrm{EtOAc}, \mathrm{Me}_{2} \mathrm{Cl}_{2}\right.$ and pet.ether). There was a correlation between antioxidant activity and total phenol content. HPLC analysis of the extracts showed that gallic and cinnamic acid was the major phenolic compounds in winery pomace. Various phenolic compounds such as catechin, rutin, rosmarinic, chlorogenic, caffeic, vanillic, coumaric acids were also identified.
\end{abstract}

Keywords: Grape pomace; Phenolic compounds; HPLC; DPPH

\section{Introduction}

There is an increased evidence for the participation of free radicals in the etiology of various diseases like cancer, diabetes, cardiovascular diseases, autoimmune disorders, neurodegenerative diseases, aging, etc [1].

Antioxidants are agents which scavenge the free radicals and prevent the damage caused by them. They can greatly reduce the damage by neutralizing the free radicals before they can attack the cells and prevent damage to lipids, proteins, enzymes, carbohydrates and DNA [2]. Antioxidants can be classified into two major classes i.e., enzymatic and non-enzymatic. The enzymatic antioxidants are produced endogenously and include superoxide dismutase, catalase, and glutathione peroxidase. The non-enzymatic antioxidants include tocopherols, carotenoids, ascorbic acid, flavonoids and tannins which are obtained from natural plant sources [3]. A wide range of antioxidants from both natural and synthetic origin has been proposed for use in the treatment of various human diseases [4]. There are some synthetic antioxidant compounds such as butylated hydroxytoluene, butylated hydroxyanisole and tertiary butyl hydroquinone, commonly used in processed foods. However, it has been suggested that these compounds have shown toxic effects like liver damage and mutagenesis [5]. Flavonoids and other phenolic compounds of plant origin have been reported as scavengers of free radicals [6].

In the last few years, an increased attention has been focused on the industrial pomaces, especially those containing phenols from residual plant raw materials. There has been an upsurge in the exploitation of the pomace materials generated by the wine industry. Wine pomace is characterized by the presence of natural antioxidants and is characterized by high-phenolic contents due to poor extraction during winemaking, and thus making their utilization worthwhile [7]. In recent years, the use of grape seed extracts (GSE) has gained ground as a nutritional supplement in view of its antioxidant activity. The by-products obtained after winery exploitation, either seeds or pomaces, constitute a very cheap source for the extraction of antioxidant flavanols, which can be used as dietary supplements, or in the production of phytochemicals, providing an important economic advantage [8] and additive value will be added to the residue. It is hoped that information on the total phenolic compounds and antioxidant activities of plant extracts and their individual phenolic compounds can be used as criteria to retard or prevent lipid oxidation in a variety of food products. The aim of this work is to investigate the effect of extracting solvents on the phenol content of winery pomace extracts and evaluate the antioxidant activity of winery pomace extracts in order to develop an effective procedure for the recovery of phenolic compounds from winery pomace with special consideration to their utilization as antioxidants for foods.

\section{Materials and Methods}

Methanol $(\mathrm{MeOH})$, ethanol $(\mathrm{EtOH})$, acetone $\left(\mathrm{Me}_{2} \mathrm{CO}\right)$, butanol $(\mathrm{BuOH})$, ethyl acetate $(\mathrm{EtOAc})$, methylene chloride $\left(\mathrm{Me}_{2} \mathrm{Cl}_{2}\right)$ and pet. ether used were in an analytical reagent grade and purchased from Merck (Darmstadt, Germany). Folin-Ciocalteau phenol reagent, Phenolic standards have from $98-99 \%$ purity and free radical 2,2-diphenyl-1-picryl-hydrazyl (DPPH) were purchased from Sigma Chemical Co. (Sigma-Aldrich Company Ltd., Great Britain).

\section{Grape pomace samples}

Four grape varieties were selected for this study, and their wastes were produced and obtained as follows:

- Grenache waste obtained from El kroom company, consist of skin and seeds (red berries).

- Thompson seedless waste obtained from El kroom company, which consist of skin only as the species is seedless one (white berries).

- Red Romy consists of skin and seeds, obtained from local market and pomace was produced in the medicinal and aromatic plants Dept. NRC (red berries).

- Crimson grape obtained from local market and pomace produced in the lab (red berries).

- Each sample was hand divided into their parts; skin, seeds and pomace.

*Corresponding author: Souad El Gengaihi, Medicinal and Aromatic Plant Department, Pharmaceutical Division, National Research Centre, Cairo, Egypt Tel: +20-2-3371010; E mail: souadgengaihi@hotmail.co.uk

Received December 18, 2013; Accepted January 25, 2014; Published February 05, 2014

Citation: Gengaihi SEI, Ella FMA, Emad MH, Shalaby E, Doha H (2014) Antioxidant Activity of Phenolic Compounds from Different Grape Wastes. J Food Process Technol 5: 296. doi:10.4172/2157-7110.1000296

Copyright: (C) 2014 Gengaihi SEl, et al. This is an open-access article distributed under the terms of the Creative Commons Attribution License, which permits unrestricted use, distribution, and reproduction in any medium, provided the original author and source are credited. 
Seed obtained were air dried and weighted, pomace was oven dried at $50^{\circ} \mathrm{C}$, then ground to a fine powder. The powdered samples were then kept at $-4^{\circ} \mathrm{C}$ until used.

\section{Extraction of total phenolic and total flavonoid compounds}

One gram of air dried pomace powdered pomace were extracted at room temperature with petroleum ether $\left(40-60^{\circ} \mathrm{C}\right)$ till complete extraction to remove lipid, waxes, pigments, sterols and non phenolic compounds. Then the mark was extracted with (acidified EtOH $(0.1 \%$ $\mathrm{HCl}), 80 \% \mathrm{EtOH}, 50 \% \mathrm{EtOH}$ and $\left.\mathrm{Me}_{2} \mathrm{CO}\right)$ several times $(10 \mathrm{ml} \mathrm{x} \mathrm{4})$ till complete extraction. The combined extract was transferred to measuring flask $100 \mathrm{ml}$. and completed to $100 \mathrm{ml}$.

\section{Estimation of total flavonoid}

The total flavonoids content was determined using the method adopted by Meda et al. [9]. Three $\mathrm{ml}$ of $2 \%$ aluminium trichloride $\left(\mathrm{AlCl}_{3}\right)$ in methanol (Fluka Chemie, Switerland) was mixed with the same volume of the extract. Absorption was read at $415 \mathrm{~nm}$ (UV.VIS, 2041 spectrophotometer) after 30 min against a blank sample consisting of a $3 \mathrm{ml} \mathrm{AlCl}_{3}$ with $3 \mathrm{ml}$ methanol. The total flavonoids content was determined using a standard curve of rutin (Sigma-Aldrich Chemie, Steinheim, Germany) as standard. The mean of three readings was used and expressed as $\mathrm{mg}$ of rutin equivalents $/ 100 \mathrm{~g}$ of air dried pomace sample.

\section{Estimation of total phenolic content}

Folin-Ciocalteu method was used to determine total phenolic content as chlorogenic acid (sigma) according to the method described by Meda et al. [9]. Concentration of the total phenol was plotted from the chlorogenic acid calibration curve. The mean of three readings was used and the total phenolic content was expressed in $\mathrm{mg}$ of chlorogenic acid equivalents / $100 \mathrm{~g}$ of air dried pomace sample).

\section{Chromatographic procedure for flavonoid and phenolic acids}

Powdered grape wastes were extracted with $\mathrm{EtOH}(80 \%)$ by soaking at room temperature. The combined methanol extracts were concentrated under reduced pressure at $45^{\circ} \mathrm{C}$. The crude residue was dissolved in hot water, left overnight, filtered and was successively partitioned with methylene chloride $\left(\mathrm{Me}_{2} \mathrm{Cl}_{2}\right)$, ethyl acetate (EtOAc) and n-butanol (BuOH). The HPLC system was a HP 1100 chromatograph (Agilent Technologies, Palo Alto, CA, USA) equipped

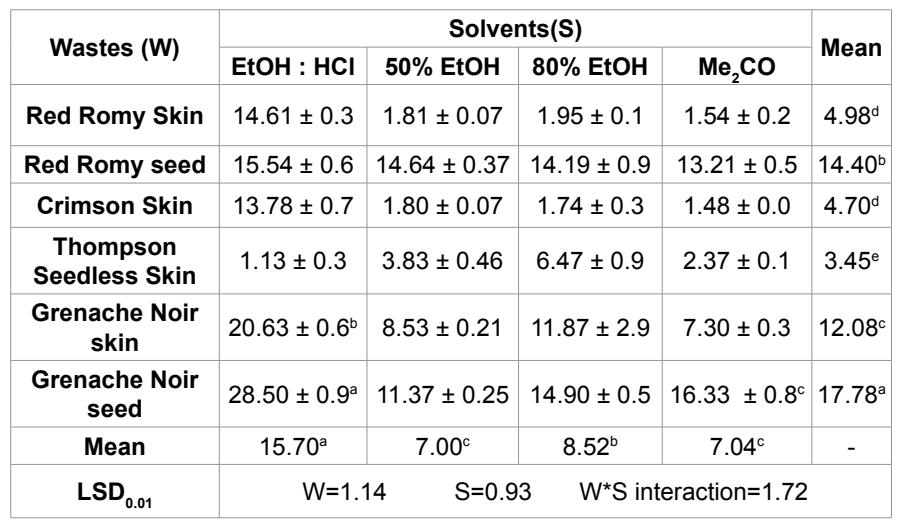

Data are represented as mean \pm S.E.

Statistical analysis is carried out by two way analysis of variance using COSTAT program.

Unshared letters between brackets are significant value between groups.

Table 1: Total phenolic content $(\mathrm{mg} / \mathrm{g})$ in different grape pomaces using different extracting solvents. with an auto-sampler, quaternary pump and a diode array detector. The measurements were integrated by Chemstation chromatographic software interfaced to a personal computer.

The analytical column was ZORBAX Eclipse XDB C18 column (15 $\mathrm{cm} \times 4.6 \mathrm{~mm}$ ID, $5 \mu \mathrm{m}$, USA). Operative conditions were: mobile phase A, methanol; mobile phase $\mathrm{B}, 2 \%$ acetic acid; flow rate, $1 \mathrm{~mL}$ min; fixed wavelength, 280 and $360 \mathrm{~nm}$; injected quantity, $20 \mathrm{uL}$; elution program, $\mathrm{A}(\%) / \mathrm{B}(\%): 0 \min 5 / 95 ; 10 \min 25 / 75 ; 20 \mathrm{~min}$ 50/50; $30 \mathrm{~min}$ 100/0; $40 \mathrm{~min} 5 / 95$. Identification of phenolic compounds was performed by comparison with the retention times of standard substances [10].

\section{DPPH radical-scavenging activity}

As described by Mahakunakorn et al. [11], scavenging capacity was measured spectrophotometrically at $517 \mathrm{~nm}$. Inhibition (\%) was plotted against the sample concentration $(100 \mathrm{ug} / \mathrm{ml}$ in $\mathrm{MeOH})$ in the reaction system; The mixture was shaken vigorously $(2,500 \mathrm{rpm})$ for $1 \mathrm{~min}$ then left to stand for $60 \mathrm{~min}$ in the dark. ascorbic acid and BHT $(100 \mathrm{ug} / \mathrm{ml}$ in $\mathrm{MeOH}$ ) were used as a positive control, the percentage inhibition of the DPPH radical was calculated according to the following formula:

$\%$ Inhibition $=(($ A control $-\mathrm{A}$ sample $) /$ control $) \mathrm{X} 100$

Where $\mathrm{A}$ is absorbance

\section{Statistical analysis}

Data were expressed by two-way analysis of variance (ANOVA), COSTAT Software Computer Program. Significance values between groups were at $\mathrm{P}<0.01$ [12].

\section{Results and Discussion}

Chemical characterization of winery pomace had prior necessity to evaluate its potential, to determine the extraction yield and to be controlled qualitatively.

\section{Total phenolic content}

Phenolic compounds react with Folin Ciocalteu's Reagent (FCR) only under basic conditions (adjusted by aqueous sodium carbonate). Dissociation of a phenolic proton in basic medium leads to a phenolate anion, which is capable of reducing FCR in which the molybdate in testing system is reduced forming a blue colored molybdenum oxide with maximum absorption near $765 \mathrm{~nm}$. The intensity of blue coloration produced is proportional to the total quantity of phenolic compounds present in the testing samples. Data of polyphenolic contents of different pomace samples are presented in Table 1. Results in Table 1 reveal that the total phenols in skin extracts were lower than in seed one; the highest concentration of total phenolic was found in Grenache noir seeds, skin and Red romy seeds. The extractive capacity of phenolic components from pomace material is considerably depend on the type of solvents. The best extraction efficiency was achieved by ethanol: $0.1 \% \mathrm{HCl}$ (acidified alcohol) and $80 \% \mathrm{EtOH}$ whereas pure ethanol resulted in poor phenolic contents. The technique of phenolic isolation from a plant material, including the methods and type of extracting solvent, depends generally on the type of phenolic compound and the solvents [13]. Results of previous studies showed that the extraction yield of phenolic and flavonoid content is greatly expressed in acidified alcohol [14], and this holds with our results.

\section{Total flavonoids}

The yields obtained by using various extractants (solvents) and their composition of total flavonoids are shown in Table 2. The highest 


\begin{tabular}{|c|c|c|c|c|c|}
\hline \multirow{2}{*}{ Wastes (W) } & \multicolumn{4}{|c|}{ Solvents (S) } & \multirow{2}{*}{ Mean } \\
\hline & EtOH : HCl & $50 \%$ EtOH & $80 \%$ EtOH & $\mathrm{Me}_{2} \mathrm{CO}$ & \\
\hline Red romy Skin & $0.71 \pm 0.00$ & $0.31 \pm 0.00$ & $0.30 \pm 0.00$ & $0.29 \pm 0.01$ & $0.40^{d}$ \\
\hline Red romy seed & $1.79 \pm 0.01 \mathrm{~b}$ & $0.65 \pm 0.00$ & $0.66 \pm 0.00$ & $0.57 \pm 0.00$ & $0.92^{c}$ \\
\hline Crimson Skin & $0.66 \pm 0.00$ & $0.39 \pm 0.00$ & $0.37 \pm 0.00$ & $0.32 \pm 0.00$ & $0.43^{d}$ \\
\hline Thompson seedless skin & $1.01 \pm 0.01$ & $0.93 \pm 0.00$ & $2.13 \pm 0.02^{a}$ & $1.54 \pm 0.01^{c}$ & $1.41^{a}$ \\
\hline Grenache noir skin & $1.42 \pm 0.02$ & $0.69 \pm 0.00$ & $0.94 \pm 0.01$ & $1.02 \pm 0.01$ & $1.02^{b}$ \\
\hline Grenache noir seeds & $1.34 \pm 0.01$ & $0.64 \pm 0.00$ & $0.74 \pm 0.01$ & $0.58 \pm 0.00$ & $0.83^{c}$ \\
\hline Mean & $1.16^{\mathrm{a}}$ & $0.60^{d}$ & $0.86^{b}$ & $0.72^{c}$ & \\
\hline $\operatorname{LSD}_{0.01}$ & \multicolumn{5}{|c|}{$W=0.10$} \\
\hline
\end{tabular}

Data are represented as mean \pm S.E.

Statistical analysis is carried out by two way analysis of variance using COSTAT program

Unshared letters between brackets are significant value between groups

Table 2: Total flavonoid content $(\mathrm{mg} / \mathrm{g})$ in different grape pomaces using different extracting solvents.

\begin{tabular}{|c|c|c|c|c|c|c|c|c|c|c|c|}
\hline \multirow[b]{2}{*}{ Wastes } & \multicolumn{11}{|c|}{ Concentration $\mathrm{mg} / 100 \mathrm{~g}$} \\
\hline & Extract & Catechin & Gallic & Caffeic & Vanillic & Cumaric & Ferulic & Cinnamic & Chlorogenic & Rosmarinic & Rutin \\
\hline \multirow{3}{*}{ Red romy skin } & EtOAc & 151 & 3.84 & - & - & - & - & 138 & 20.7 & - & 20.8 \\
\hline & $\mathrm{BuOH}$ & 0.91 & 7.09 & - & - & - & 2.85 & - & 2.44 & - & - \\
\hline & $\mathrm{EtOH}$ & 2.78 & 30.6 & 5.49 & 6.21 & 0.85 & 3.88 & 37.7 & 8.21 & 187 & 52.2 \\
\hline \multirow{3}{*}{$\begin{array}{l}\text { Red romy } \\
\text { seeds }\end{array}$} & EtOAc & 6.81 & 16.4 & - & 9.55 & - & 5.25 & 7.47 & 6.56 & - & 104 \\
\hline & $\mathrm{BuOH}$ & 20.4 & 366 & - & 171 & 4.48 & 235 & 2690 & 49.1 & 218 & 482 \\
\hline & $\mathrm{EtOH}$ & - & 212 & - & 94.5 & 114 & 216 & 1146 & 370 & 7.98 & 17.2 \\
\hline \multirow{3}{*}{ Crimson skin } & EtOAc & - & 6.34 & 6.8 & 1.61 & - & - & 1949 & 59.1 & 16.4 & 129 \\
\hline & $\mathrm{BuOH}$ & 4.31 & 85 & - & 26.2 & 46.3 & - & 425 & - & 79.2 & 996 \\
\hline & $\mathrm{EtOH}$ & 1.62 & 23.9 & 5.56 & - & 15.6 & 4.68 & 82.4 & - & 2.71 & 207 \\
\hline \multirow{3}{*}{$\begin{array}{l}\text { Thompson } \\
\text { seedless } \\
\text { skin }\end{array}$} & EtOAc & 2.68 & 82.5 & 29.6 & 0.51 & - & - & 4.81 & 16.3 & 51.2 & 9.63 \\
\hline & $\mathrm{BuOH}$ & 5.93 & 15.3 & 26 & 6.76 & 2.39 & - & 518 & - & 55.6 & 866 \\
\hline & $\mathrm{EtOH}$ & 7.53 & 1058 & 231 & 4.34 & 90 & 36.6 & 457 & - & 453 & 749 \\
\hline \multirow{3}{*}{$\begin{array}{l}\text { Grenache noir } \\
\text { skin }\end{array}$} & EtOAc & 0.57 & 3.99 & 17.7 & - & - & 12.8 & - & 20.2 & - & - \\
\hline & $\mathrm{BuOH}$ & 15.3 & 48.8 & 22.3 & 11.6 & 1.53 & 88 & 42 & 30.2 & - & 75.3 \\
\hline & $\mathrm{EtOH}$ & - & 22.6 & 29.8 & 2.1 & 46.1 & 91.8 & 187 & - & 116 & 284 \\
\hline \multirow{3}{*}{$\begin{array}{l}\text { Grenache noir } \\
\text { seeds }\end{array}$} & EtOAc & - & 3.48 & 6.04 & - & - & - & - & - & - & - \\
\hline & $\mathrm{BuOH}$ & 7.93 & 67.8 & 153 & 11.8 & 1.72 & - & 105 & 24.1 & - & 5.54 \\
\hline & $\mathrm{EtOH}$ & - & 77.1 & 15.6 & 26.6 & 11.7 & 12.1 & 56.4 & 61.3 & - & 43 \\
\hline
\end{tabular}

Table 3: concentration of phenolic acids $(\mathrm{mg} / 100 \mathrm{~g})$ in the investigated samples by HPLC

flavonoid content was found in Thompson pomace and the lowest one were in red romy skin and crimson skin.

\section{High Performance Liquid Chromatography (HPLC)}

It is obvious that the total phenolic content measured by the Folin-Ciocalteu procedure does not give a full picture of the quality or quantity of the phenolic constituents in the extracts as reported in literature $[15,16]$. PLC is the preferred technique for both separation and quantification of phenolic compounds [17]. Various factors affect HPLC analysis of phenolics, including sample purification, mobile phase, column types and detectors [18]. In general, purified phenolics are applied to an HPLC instrument utilizing a reversed phase C18 column (RP-C18), photo diode array detector (PDA) and polar acidified organic solvents [19]. The HPLC analysis of the phenolic compounds in different extracts (EtOAc, $\mathrm{BuOH}$ and $80 \% \mathrm{EtOH}$ ) were employed using the previous condition and were compiled in Table 3. HPLC analysis of different extracts of grape pomace showed a complex mixture of phenolics that was difficult to resolve. Several phenolic compounds, which are representative of the diverse structural types, were identified. Table 3 reveals that the alcoholic extract of romy seeds had the highest amounts of ferulic, coumaric, vanillic, chlorogenic $(216,114,94$, and $370 \mathrm{ug} / 100 \mathrm{~g}$ respectively). While Thompson seedless pomace had the highest amount of gallic, caffeic and rosmarinic acid (1058, 231 and $453 \mathrm{ug} / 100 \mathrm{~g}$ respectively). Butanolic extract of Crimson skin had the highest rutin amount (996 ug/100g); while the butanolic extract of romy seeds had the highest cinnamic acid amount (2690ug/100g).

These finding are in agreement with Kallithraka et al. [20] they indicated that the ethanol extraction of grape seed had high content of catechin, Rodtjer et al. [21] showed that the extraction yield of phenolic compounds is greatly depending on the solvent polarity [22]. According to Yilmaz and Toledo [23] they concluded that aqueous solutions of ethanol, methanol was better than a pure compound solvent system for the extraction of phenolics compound from Muscadine seed. Also, other studies have established that the phenolics and flavonoids content of extracts are strongly depend on the type of the solvent as well as on the different concentrations used.

Wang and Helliwell [24] reported that aqueous ethanol was better than aqueous methanol for extraction of tea flavonoids. In extracting phenolic compounds from peanut skin, ethanol and methanol were more effective than water, with ethanol being the most efficient extraction solvent [25]. Meanwhile, the methanol was the solvent with best results for phenols from pine sawdust, while in almond hulls ethanol was the best extraction solvent [26]. Jung et al. [27] compared the influence of different solvents and they found out that the ethanol extracts contained higher amounts of total phenolics and flavonoids than water and methanol extracts from wild ginseng leaves. 
Citation: Gengaihi SEI, Ella FMA, Emad MH, Shalaby E, Doha H (2014) Antioxidant Activity of Phenolic Compounds from Different Grape Wastes. J Food Process Technol 5: 296. doi:10.4172/2157-7110.1000296

Page 4 of 5

\begin{tabular}{|c|c|c|c|c|c|c|}
\hline \multirow[b]{2}{*}{ Wastes } & \multicolumn{5}{|c|}{ Inhibition \% $\quad(100 \mathrm{ul} / \mathrm{ml})$} & \multirow[b]{2}{*}{ Mean } \\
\hline & EtOH & EtOAc & $\mathrm{BuOH}$ & $\mathrm{Me}_{2} \mathrm{Cl}_{2}$ & Pet.ether & \\
\hline Romy Skin & $81.94 \pm 2.69$ & $24.25 \pm 0.4$ & $25.15 \pm 0.5$ & $25.8 \pm 1.8$ & $23.6 \pm 0.0$ & 36.1 \\
\hline Romy seeds & $93.31 \pm 1.27^{\mathrm{a}}$ & $59.9 \pm 1.3$ & $64.1 \pm 3.2$ & $26.6 \pm 0.8$ & $27.3 \pm 1.8$ & $54.2^{\mathrm{b}}$ \\
\hline Crimson skin & $74.33 \pm 2.44$ & $26.1 \pm 1.4$ & $27.3 \pm 0.9$ & $23.6 \pm 0.0$ & $27.3 \pm 0.9$ & 35.7 \\
\hline Thompson seedless skin & $89.05 \pm 2.04$ & $54.05 \pm 0.5$ & $33.15 \pm 0.4$ & $29.1 \pm 0.9$ & $27.1 \pm 0.9$ & 46.5 \\
\hline Grenache noir & $91.47 \pm 2.55$ & $72.25 \pm 2.3$ & $47.3 \pm 0.4$ & $26.35 \pm 1.8$ & $20.6 \pm 1.8$ & 51.6 \\
\hline Grenache noir seeds & $90.23 \pm 1.02$ & $100 \pm 0.5$ & $79.2 \pm 0.7$ & $27.8 \pm 0.09$ & $23.8 \pm .6$ & $64.2^{\mathrm{a}}$ \\
\hline Mean & $86.7^{\mathrm{a}}$ & 56.1 & 46 & 26.5 & 25 & \\
\hline Ascorbic & \multicolumn{5}{|c|}{$90.15 \pm 2.5$} & \\
\hline BHT & \multicolumn{5}{|c|}{$94.1 \pm 2.03$} & \\
\hline
\end{tabular}

Data are represented as mean \pm S.E.

Statistical analysis is carried out by two way analysis of variance using COSTAT program

Unshared letters between brackets are significant value between groups

Table 4: In vitro DPPH radical scavenging activity of different grape pomaces extracted with different solvents.

\section{Antioxidant activity}

The most common methods to determine antioxidant activity in a practical, rapid and sensitive manner are those that involve a radical chromophore, simulating the reactive oxygen species, and the free radical $\mathrm{DPPH}$, of purple coloration that absorbs at $515 \mathrm{~nm}$, is one of the most widely used for in vitro evaluation of plant extracts and fractions. Dealing with antioxidant activity of different grape pomaces extracted by different solvent, Table 4 reveals that ethanol extract of different pomaces produced the higher radical scaveniging activity when compared with other solvents i.e. EtOAc, $\mathrm{BuOH}, \mathrm{Me}_{2} \mathrm{Cl}_{2}$ and Pet. ether solvents. Alcoholic extract of Red romy seeds gave the highest antioxidant activity than ascorbic and other grape pomaces; which may be attributed to its major components of phenolic acids like ferulic, coumaric, vanillic, gallic, chlorogenic and cinnamic. The different antioxidant activities of phenolic extracts can be attributed to different extracting solvent as the antioxidant activity depends on the type and polarity of the extracting solvent, the isolation procedures, the purity of active compounds, as well as the test system [28].

EtOAc, BuOH, Pet.ether extracts exhibited lower antioxidant activity than $\mathrm{EtOH}$, The high antioxidant activity of ethanol extract can be also attributed to its major components, i.e. gallic acid and catechin. There is one exception that EtOAc of Grenache noir exhibited the highest antioxidant activity.

A positive correlation was well established with the EtOH of romy seeds and Grenache noir seeds where the highest values of polyphenols ( 14.2 and $14.9 \mathrm{mg} / \mathrm{g}$ respectively) in this fractions relate to the good DPPH radical inhibition results (93.31 and $90.23 \%$ respectively). This correlation between phenolics compounds and the antioxidant capacity (DPPH method) is in good agreement with the results of Mustafa et al. [29], Surveswaran et al. [30] and Janovik et al. [31].

Some studies suggest that it is not always possible to correlate the total phenolics and antioxidant capacity. This can be explained by several factors, including the presence of different active compounds in the plant that can modify the antioxidant capacity, the synergistic effects of different compounds, the experimental conditions, and the mechanisms of the methods used for antioxidant reactions. Structural factors include the nature of the phenolic groups and the changes caused by glycosylation [32]. There are also compounds that react strongly with the DPPH, and others that have a slower reaction rate [33].

\section{References}

1. Bandyopadhyay U, Das A, Bannerjee RK (1999) Reactive oxygen species: Oxygen damage and pathogenesis. Curr Sci 77: 658-666.
2. Fang Y, Yang S, Wu G (2002) Free radicals, antioxidants and nutrition. Nutrition 18: $872-879$

3. Lee J, Koo N, Min DB (2004) Reactive oxygen species, aging and antioxidative nutraceuticals. CRFSFS 3: 21-33.

4. Cuzzocrea S, Riley DP, Caputi AP, Salvemini D (2001) Antioxidant therapy: A new pharmacological approach in shock, inflammation and ischemia/ reperfusion injury. Pharmacol Rev 53: 135-159.

5. Wichi HP (1988) Enhanced tumour development by butylated hydroxyanisole (BHA) from the prospective of effect on forestomach and oesophageal squamous epithelium. Food Chem Toxicol 26: 717-723.

6. Rice-Evans CA, Miller NJ, Paganaga G (1997) Antioxidant properties of phenolic compounds. Trends Plant Sci 2: 152-159.

7. Kammerer D, Claus A, Carle R, Schieber A (2004) Polyphenol screening of pomace from red and white grape varieties (Vitis vinifera $L$.) by HPLC-DAD-MS/ MS. Journal of Agricultural Food and Chemistry 52: 4360-4367.

8. Gonzalez-Paramas A, Esteban-Ruano S, Santos-Buelga C, Pascual-Teresa S, Rivas-Gonzalo J (2004) Flavanol content and antioxidant activity in winery byproducts. Journal of Agricultural Food and Chemistry 52: 234-238.

9. Meda A, Euloge C, Marco L, Jeanne R, Nacoulma OG (2005) Determination of the total phenolic, flavonoid and proline contents in Burkina Fasan honey, as well as their radical scavenging activity. Food Chemistry 91:571-577.

10. Leonardis A, Macciola V, Domenico N (2005) A first pilot study to produce a food antioxidant from sunflower seed shells (Helianthus annuus). Eur J Lipid Sci Technol 107: 220-227.

11. Mahakunakorn P, Tohda M, Murakami Y, Matsumoto K, Watanabe H (2004) Antioxidant and free radical-scavenging activity of Choto-san and its related constituents. Biol Pharm Bull 27: 38-46.

12. Steel R, Torrie J (1981) Principles and Procedures of Statistics: A Biometrical Approach. 2nd edition. McGraw-Hill Book Co., New York, $633 \mathrm{p}$

13. Goli AH, Barzegar M, Sahari MA (2004) Antioxidant activity and total phenolic compounds of pistachio (Pistachia vera) hull extracts. Food Chem 92: 521-525.

14. Lapornik B, Prosek M, Wondra AG (2005) Comparison of extracts prepared from plant by-products using different solvents and extraction time. J Food Eng 71: $214-222$

15. Katsube T, Tabata H, Ohta Y, Yamasaki Y, Anuurad E, et al. (2004) Screening for antioxidant activity in edible plant products: Comparison of low-density lipoprotein oxidation assay, DPPH radical scavenging assay, and FolinCiocalteu assay. Journal of the Agricultural and Food Chemistry 52: 2391-2396.

16. Wu X, Beecher GR, Holden JM, Haytowitz DB, Gebhardt SE, et al. (2004) Lipophilic and hydrophilic antioxidant capacities of common foods in the United States. Journal of the Agricultural and Food Chemistry 52: 4026-4037.

17. Naczk M, Shahidi $F$ (2004) Review: Extraction and analysis of phenolics in food. J Chromatogr A 1054: 95-111.

18. Stalikas CD (2007) Review: Extraction, Separation, and detection methods for phenolic acids and flavonoids. J Sep Sci 30: 3268-3295.

19. Ignat I, Volf I, Popa VIA (2011) Critical review of methods for characterization of polyphenolic compounds in fruits and vegetables. Food Chem 126: 1821-1835. 
Citation: Gengaihi SEI, Ella FMA, Emad MH, Shalaby E, Doha H (2014) Antioxidant Activity of Phenolic Compounds from Different Grape Wastes. J Food Process Technol 5: 296. doi:10.4172/2157-7110.1000296

20. Kallithraka S, Garcia-Viguera C, Bridle P, Bakker J (1996) Survey of solvents for the extraction of grape seed phenolics. Phytochem Anal 6: 265-267.

21. Rodtjer A, Skibsted LH, Andersen ML (2006) Antioxidative and prooxidative effect of extracts made from cherry liqueur pomace. Food Chem 99: 6-14.

22. Turkmen N, Sari F, Velioglu YS (2006) Effects of extraction solvents on concentration and antioxidant activity of black and black mate tea polyphenols determined by ferrous tartrate and Folin-Ciocalteu methods. Food Chem 99 : 835-841.

23. Yilmaz Y, Toledo RT (2004) Major flavonoids in grape seeds and skins antioxidant capacity of catechin, epicatechin and gallic acid. J Agric Food Chem 52: $255-260$

24. Wang $\mathrm{H}$, Helliwell K (2001) Determination of flavonols in green and black tea leaves and green tea infusions by high-performance liquid chromatography. Food Res Int 34: 223-227.

25. Yu J, Ahmedna M, Goktepe I (2005) Effects of processing methods and extraction solvents on concentration and antioxidant activity of peanut skin phenolics. Food Chem 90: 199-206.

26. Pinelo M, Rubilar M, Sineiro J, Nunez MJ (2004) Extraction of antioxidant phenolics from almond hulls (Prunus amygdalus) and pine sawdust (Pinus pinaster). Food Chem 85: 267-273.
27. Jung $\mathrm{CH}$, Seog HM, Choi IW, Park MW, Cho HY (2006) Antioxidant properties of various solvent extracts from wild ginseng leaves. Food Sci Thecnol 39: 266-274.

28. Meyer AS, Heinonen M, Frankel EN (1998) Antioxidant interactions of catechin, cyaniding, caffeic acid, quercetin and ellagic acid on human LDL oxidation. Food Chemistry 61: 71-75

29. Mustafa RA, Hamid AA, Mohamed S, Bakar FA (2010) Total Phenolic Compounds, Flavonoids, and Radical Scavenging Activity of 21 Selected Tropical Plants. J Food Sci 75: 28-30.

30. Surveswaran S, Cai YZ, Corke H, Sun M (2007) Systematic evaluation of natural phenolic antioxidants from 133 Indian medicinal plants. Food Chem 102: 938-953.

31. Janovik V, Boligon AA, Bandeira RV, Athayde ML (2011) HPLC/DAD analysis determination of total phenolic and flavonoid contents and antioxidant activity from the leaves of Cariniana domestica (Mart) Miers. Res J Phytochem 5 : 209-215.

32. Cho EJ, Yokozava T, Rhyu DY, Kim SC, Shibahara N, Park JC (2003) Study on the inhibitory effects of Korean medicinal plants and their main compounds on the DPPH radical. Phytomedicine 10: 544-551.

33. Tsimogiannis DI, Oreopoulou V (2006) The contribution of flavonoids C-ring on the DPPH free radical scavenger efficiency. A kinetic approach for the 30,40-hydroxy substituted members. Food Sci Emerging Technol 7: 140-146. 